Volume 2, Number 1, January 2020

\title{
Original Article \\ Study on knowledge, attitude and practice of personal hygiene among selected rural people
}

\author{
Muiz Uddin Ahmed Choudhury, ${ }^{1}$ Monowar Ahmad Tarafdar, ${ }^{2}$ Md. Abdul Mojid Miah, ${ }^{3}$ Shila Rani Das, ${ }^{4}$ \\ Tonim Amir Haque, ${ }^{5}$ Syed Shawkat Ahmed ${ }^{6}$
}

\begin{abstract}
:
Descriptive type of Cross sectional study conducted in Jaintapur Upazila from the period of October-December 2017 to assess knowledge, attitude and practice of personal hygiene among selected rural people with a sample size of 308 using a semi-structured questionnaire following purposive sampling technique. Out of 308 respondents about three fourth of respondents were Muslims, $55.8 \%$ were male. More than half were in the age group $15-35$ years, $85.7 \%$ were married, $44.5 \%$ were Illiterates. $30.4 \%$ were house wife and only $6 \%$ had their monthly income $\geq$ Tk. 30,000. Almost 286(92.8\%) respondents had knowledge on importance of hand washing, majority 244(79.2\%) had knowledge about transmission of Communicable disease by Hand contamination. Regarding factors causes discouraging from hand washing about 123(39.9\%) respondents forget to wash, 74(24\%) feel Shortage of time and 70(22.8\%) not known. Only $13 \%$ of respondents wore ring during cooking and food handling. Almost 290(94.2\%) washed hand before eating, 298(96.8\%) washed their hand after coming back from the toilet and 301(97.7\%) respondents had habit of Cutting Nail. Majority of them 234 (78.5\%) used soap for hand washing after coming back from latrine, only 1(0.3\%) used liquid hand wash and others respectively. About (84.1\%) discussed about hand washing with their children and family members and 238(77.3\%) respondent's children's habit of hand washing of children before taking food \& after toilet. More than half of respondents got information from Radio and Television, 79(25.6\%) from health educator, 17(5.5\%) from others. Awareness of general people about hand washing and its practices should be increased within earliest possible time through behavior Change Communication (BCC) programme of $\mathrm{GO} / \mathrm{NGO}$ partnership should be planned with more emphasis on hand washing.
\end{abstract}

\section{Key words: Knowledge, Practice, Attitude, Rural people}

\section{Introduction:}

Health is the quality of life that renders the individual fit to live most and serve best. Personal hygiene or personal health care deals with measures which are the personal responsibilities of the individual for the promotion of good health. ${ }^{1}$ For healthful growth and development, cleanliness plays an important role. The child in a family should be trained to develop the habit of washing his hands before and after eating and after using the toilet. ${ }^{1}$ Even though proper hand washing is the most effective and easiest way to prevent many diseases, unfortunately many people do not practice hand washing correctly. ${ }^{3}$

Public health importance of hand washing as well as its importance in reduction of communicable diseases such as diarrhea and acute respiratory infections have been highlighted in many studies worldwide. ${ }^{4}$ It can

significantly reduce the two biggest causes of childhood death- diarrhoeal disease and acute respiratory infections such as the flu. Good hand washing requires water, soap and ideally clean hand drying facilities. But most importantly there must be hygiene promotion to encourage hand washing after using the toilet, before handling food, changing a child's nappy and after touching animals and before eating. ${ }^{5}$

\section{Materials and Methods:}

Descriptive type of Cross sectional study conducted in Jaintapur Upazila from the period of October-December 2017 with a sample size of 308 among the respondents age 15 years and above to assess knowledge, attitude and practice of personal hygiene among selected rural people using a semi structured questionnaire employing purposive sampling technique. Data was collected by face to face interview and checked and cleaned for

1. Assistant Professor, Department of Community Medicine, Jalalabad Ragib -Rabeya Medical College, Sylhet

2. Professor, Department of Community Medicine, Z H Sikder Women's Medical College Dhaka

3. Professor, Department of Community Medicine, Jalalabad Ragib -Rabeya Medical College, Sylhet

4. Associate Professor, Department of Community Medicine, Z H Sikder Women's Medical College Dhaka

5. MPH student, National Institute of Preventive and Social Medicine, Dhaka

6. Associate Professor, Department of Dermatology, Jahurul Islam Medical College, Bajitpur

Address of correspondence:

Muiz Uddin Ahmed Choudhury, Assistant Professor, Department of Community Medicine, Jalalabad Ragib -Rabeya Medical College, Sylhet. 
inconsistencies. Data were analyzed manually and by using calculator and computer.

\section{Results}

About three fourth 85.1\%, of respondents were Muslims, $55.8 \%$ were male. More than half were in the age group $15-$ 35 years; only $7.1 \%>65$ years. Majority of the respondents $(85.7 \%)$ were married, $44.5 \%$ were Illiterates and only 23(7.4\%) have their education level H S C and above. About $30.4 \%$ were house wife followed by $20.3 \%$ daylabor, $16 \%$ farmer, $14.7 \%$ businessman and $4.2 \%$ service holder. About 27\% monthly income Tk. 1000 to 5000 and only $6 \%$ had their monthly income $\geq$ Tk. 30,000 . Almost 286(92.8\%) respondents had knowledge on importance of hand washing. Majority 244(79.2\%) had knowledge about transmission of Communicable disease by Hand contamination. Regarding factors causes discouraging from hand washing about $123(39.9 \%)$ respondents forget to wash, 74(24\%) feel Shortage of time and 70(22.8\%) not known (Table 1). Only 13\% of respondents wore ring during cooking and food handling. Almost 290(94.2\%) washed hand before eating, 298(96.8\%) washed their hand after coming back from the toilet and 301(97.7\%) respondents had habit of Cutting Nail (Table 2). Majority of them 234 (78.5\%) used soap for hand washing after coming back from latrine, $49(16.4 \%)$ used only running water, $6(2.1 \%)$ used ash, $6(2.1 \%)$ used soil and only $1(0.3 \%)$ used liquid hand wash and others respectively (Figure 1).About $76 \%$ used sanitary latrine (Figure 2) Majority of respondents 259 (84.1\%) discussed about hand washing with their children and family members and $238(77.3 \%)$ respondent's children's habit of hand washing of children before taking food \& after toilet (Table 3). More than half of respondents 193(62.7\%) got information from Radio and Television, 79(25.6\%) from health educator, $17(5.5 \%)$ from others, $7(3.3 \%)$ had no response, $8(2.6 \%)$ from bill board, $4(1.3 \%)$ from newspaper (Table 4).

Table 1: Knowledge on personal hygiene $(n=308)$

\begin{tabular}{l|l|l}
\hline $\begin{array}{l}\text { Knowledge on personal } \\
\text { hygiene }\end{array}$ & Frequency & Percentages \\
\hline \multicolumn{3}{l|}{ Knowledge on importance of hand washing } \\
Yes & 286 & 92.8 \\
No & 22 & 7.2 \\
\hline \multicolumn{3}{l}{ Knowledge about transmission of Communicable disease } \\
by Hand contamination. \\
\hline Yes & 244 & 79.2 \\
No & 64 & 20.8 \\
\hline
\end{tabular}

Factors causes discouraging from hand washing

\begin{tabular}{lll}
\hline Shortage of time & 74 & 24 \\
Forget to wash & 123 & 39.9
\end{tabular}

\begin{tabular}{lll} 
Inadequate facilities & 22 & 7.2 \\
Work takes priority & 18 & 5.8 \\
Others & 01 & 0.3 \\
Not known & 70 & 22.8 \\
Total & 308 & 100 \\
\hline
\end{tabular}

Table 2: Distribution of respondents by personal hygiene Practice $(\mathbf{n}=308)$

\begin{tabular}{lll}
\hline Hygiene practice & Frequency & Percentages \\
\hline \multicolumn{3}{l}{ Wear rings during cooking and food handling } \\
Yes & 39 & 13 \\
No & 269 & 87 \\
\hline \multicolumn{2}{l}{ Washing hand before eating food } \\
\hline Yes & 290 & 94.2 \\
No & 18 & 5.8 \\
\hline Washing hand after coming from toilet & \\
\hline Yes & 298 & 96.8 \\
No & 09 & 2.9 \\
Non response & 01 & 0.3 \\
\hline Habit of cutting nail & & \\
\hline Yes & 301 & 97.7 \\
No & 07 & 2.3 \\
Total & 308 & 100 \\
\hline
\end{tabular}

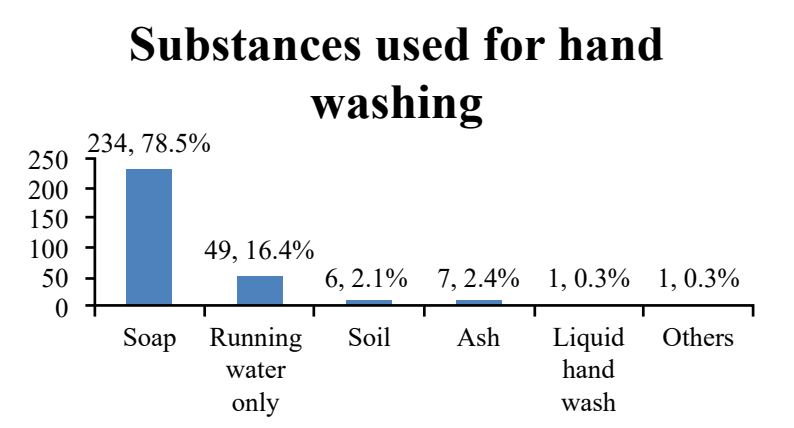

Figure 1: Substances used for hand washing after coming from toilet. $(n=308)$

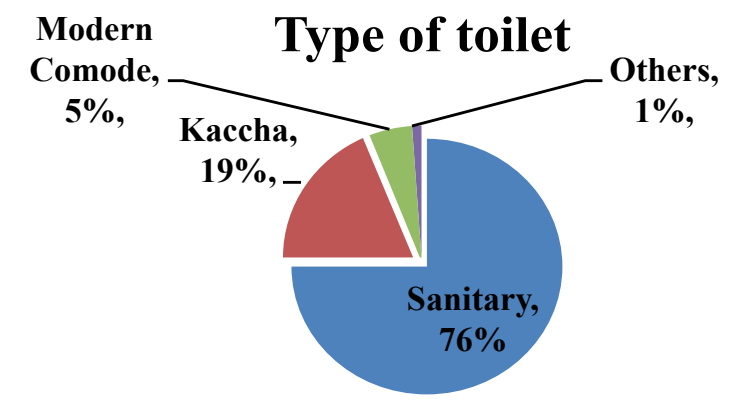

Figure 2: Type of toilet used 
Table 3: Respondents attitude regarding personal hygiene

\begin{tabular}{l|l|l}
\hline $\begin{array}{l}\text { Attitude regarding personal } \\
\text { hygiene }\end{array}$ & Frequency & Percentages \\
\hline $\begin{array}{l}\text { Discussed about hand washing with their children and } \\
\text { family members }\end{array}$ & 259 & 84.1 \\
Yes & 41 & 13.3 \\
No & 08 & 2.6 \\
Non response & & \\
Habit of hand washing of children before taking food \& \\
after toilet & 238 & 77.3 \\
Yes & 52 & 16.9 \\
No & 18 & 5.8 \\
Non response & 308 & 100 \\
\hline
\end{tabular}

Table 4: Sources of getting information $(n=308)$

\begin{tabular}{l|l|l}
\hline $\begin{array}{l}\text { Sources of getting } \\
\text { information }\end{array}$ & Frequency & Percentages \\
\hline Radio/ TV & 193 & 62.7 \\
Newspaper & 4 & 1.3 \\
Health educator & 79 & 25.6 \\
Billboard & 8 & 2.6 \\
Others & 17 & 5.5 \\
Non-response & 7 & 3.3 \\
Total & 308 & 100 \\
\hline
\end{tabular}

\section{Discussion:}

In this cross sectional study, data were collected purposively from 308 respondents. Majority of them were Muslims (85.1\%), among them $55.8 \%$ were male and $43.2 \%$ were female. More than $50 \%$ of the respondents were in the age between 15 and 35 years. Most of the respondents $(85.7 \%)$ were married. A big proportion of them $(44.5 \%)$ were illiterate, only $23 \%$ respondents have their education level HSC and above. This is the general characteristics of Bangladeshi rural population and is supported by the findings in Population and Housing Census 2011, Bangladesh. ${ }^{12}$ About occupation, 30.4\% were house wife, 20.3 were day-labor, $16 \%$ were farmer. Only about $6 \%$ had their monthly income Tk. 30,000 or more, about $27 \%$ of them had monthly income in the range of Tk. 1000 to 5000 . Majority of the family $(39.4 \%)$ have children up to 3 . About $50 \%$ families have their children number ranging 4 to 6 . This finding is similar to the findings of Bangladesh Demographic and Health Survey (BDHS) 2011, although the economic status was a bit different as the study area was around a market place where the residents were mostly involved in manual works of transporting coal and stone. ${ }^{13}$

Present study revealed that $(93 \%)$ respondents were aware about hand washing as regarding to prevention of diseases $79.2 \%$ said that transmission of communicable diseases occur through contaminated hand. Similar findings were observed in a report in USA in the year 2009. ${ }^{15}$ About $40 \%$ respondents pointed to absent mindedness for the purpose, $24 \%$ about shortage of time and $7.2 \%$ said about inadequate facilities. Similar finding was observer in a study in Ghana in the year 2009. ${ }^{20}$

Twelve percent of the respondents wore ring during their working hour. Most of them (94.2\%) washed hand before eating and $96.8 \%$ washed their hand after coming back from the toilet. A great majority of them (78.6) were used soap for hand washing after coming back from latrine and $16.4 \%$ used only running water. Use of ash and soil for the purpose was $2.3 \% \& 2.1 \%$ respectively. Slightly different findings were observed in Indonesia in the year $2007 .{ }^{16}$

In the current study it was revealed that almost $98 \%$ respondents cut their nail regularly. They used different types of latrine; majority of them used sanitary latrine $(80.1 \%)$. Slightly different findings were presented in a study in Iraq in the year 2008. The difference in the findings probably due to that most of the Iraqi people use spoon instead of bare hand as in Bangladesh. ${ }^{17}$

Most of the respondents (84.1\%) used to discuss the matter with their children and family members; $77.3 \%$ of them also followed up of their children's hand washing practice. Similar data was found in a study conducted by Department of Health, University of Hong Kong on April $2004 .{ }^{19}$

A clear-cut majority of them (62.7) uttered the name of common mass media - Radio and Television. A quarter of them get their information from health educator i.e., grass root level health workers. Role of Newspaper, Bill board or other media was not so significant. Similar finding was also observed in a study in Austria in the period JanuaryFebruary 2013. ${ }^{21}$

\section{Conclusion}

Awareness of general people about hand washing and its practices should be increased within earliest possible time through behavior Change Communication (BCC) programme of GO/NGO partnership should be planned with more emphasis on hand washing.

\section{References:}

1. Rahman M, Alamgir AKM amd Hafez MA, Rashid, Khabir, Hyder's Text Book of Community Medicine and Public Health, $5^{\text {th }}$ Ed, 2012, MAH Publishes, Uttara, Dhaka. 
Volume 2, Number 1, January 2020

2. Perk K, Perk's Text Book of Preventive and Social Medicine, $20^{\text {th }}$ Ed, 2009, M/s Banarsidas Bhanot, 1167, Prem Nagar, Nagpur Road, Jabalpur, India.

3. Setyautami T, Sermsri S and Chompikul J, Proper hand washing practices among elementary school students in Selat sub-district, Indonesia Journal of Public Health and Development, May - August 2012; 10(2).

4. Ray SK, Zaman FA, Laskar NB, Hand washing practices in two communities of two states of Eastern India: an intervention study, Indian J Public Health. 2010 Jul-Sep;54(3):126-30.

5. Halder A K, Tronchet C, Akhter S, Bhuiya A, Johnston R and Luby S P, Observed hand cleanliness and other measures of handwashing behavior in rural Bangladesh, BMC Public Health. 2010.

6. Hoque B, Handwashing practices and challenges in Bangladesh, International Journal of Environmental Health Research, June 2003; 13(1):S81-S87(7).

7. Laura R G, Carol A S, Vincent R, Danny R, James C M, David W R, Tammi S, Michelle MR, et all, Food Worker Hand Washing Practices: An Observation Study, Journal of Food Protection 2006; 69 (10):2417-2423.

8. Paulson, D. 1999. A suggested method for evaluating food handler/processor handwash formulations.Dairy Food Environ. Sanit.19: 546-550.

9. Food and Drug Administration, U.S. Public Health Service, Food Code, 2009

10. Public-Private Partnership for Handwashing with Soap (PPPHW). Global hand washing guidelines. Planners guide. 2009.

11. United Nations Children's Fund Water, Sanitation, and Hygiene Annual Report.

12. 2011 Population \& Housing Census: Preliminary Results, Bangladesh Bureau of Statistics, Statistics Division, Ministry of Planning, Government of the People's Republic of Bangladesh.

13. Bangladesh Demographic and Health Survey (BDHS) 2011, National Institute of Population Research and Training, Dhaka, Bangladesh.

14. Altun I, Cinar N D, and Dede C, Hygiene behaviour in university students in Turkey, Journal of Pakistan Medical Association, 63: 585.

15. Barbar S, Leege E and Richardson E, Reducing Morbidity and Mortality of Diarrheal Disease in Children Under 5: Intervention, Implementation, and Evaluation Plan, Washington University in St.Luis.

16. Setyautami T, Sermsri S and Chompikul J, Proper hand washing practices among elementary school students in Selat sub-district, Indonesia Journal of Public Health and Development,10(2) May - August 2012.

17. Comprehensive food security and vulnerability analysis, $\mathrm{Nu}-$ trition Research Institute, Ministry of Health, Iraq in collaboration with United Nations World Food Programme, 2008.

18. Nasreen S, Azziz-Baumgartner E, Gurley E. S., Winch P. J., Unicomb L., Sharker M. A. Y., et al, Prevalent high-risk respiratory hygiene practices in urban and rural Bangladesh, Tropical Medicine \& International Health, June 2010; 15(6): 762-771.

19. Personal and Environmental Hygiene Survey, Central Health Education Unit, Department of Health, University of Hong Kong.

20. Nkansah A, Management of faecal sludge in the urban areas of low-income countries: a case of Tamale, Ghana, A Doctoral Thesis. Submitted in partial fulfillment of the requirements for the award of Doctor of Philosophy of Loughborough University.

21. Verena GH, Paul Schlumm and Harald HK, Knowledge of and Adherence to Hygiene Guidelines among Medical Students in Austria, Interdisciplinary Perspectives on Infectious Diseases, $2013 ; 6$. 